\title{
Outcome of SARS-CoV-2 Infection in 121 Patients with Inborn Errors of Immunity: A Cross-Sectional Study
}

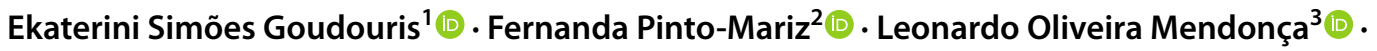

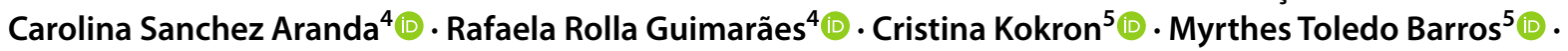

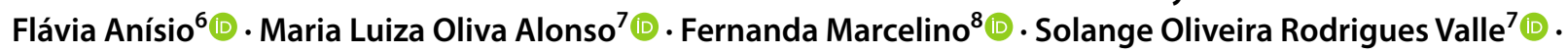

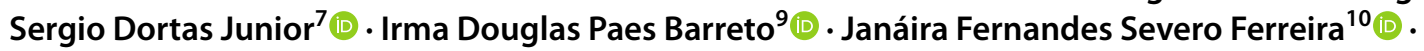

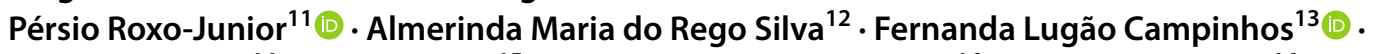 \\ Carmem Bonfim ${ }^{14}$. Gisele Loth ${ }^{15}$. Juliana Folloni Fernandes ${ }^{16}$. Julia Lopes Garcia ${ }^{16}$. Albertina Capelo ${ }^{17}$. \\ Olga Akiko Takano ${ }^{18}$ (D) Maria Isabel Valdomir Nadaf ${ }^{18}$ (1) Eliana C. Toledo ${ }^{19}$ - Luciana Araújo Oliveira Cunha ${ }^{20}$ (1) \\ Regina Sumiko Watanabe Di Gesu' ${ }^{21}$ - Laire Schidlowski ${ }^{22}$ (1) Priscila Fillipo ${ }^{23}$ (1) Daniélli C. Bichuetti-Silva ${ }^{24}$ (1) \\ Gustavo Soldateli ${ }^{25}$ (1) Natasha Rebouças Ferraroni ${ }^{26}$ (1) . Ellen de Oliveira Dantas ${ }^{27} \cdot$ Simone Pestana $^{28}$.

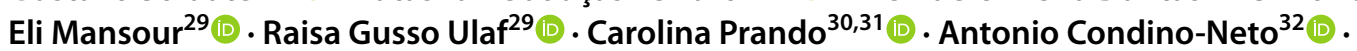 \\ Anete Sevciovic Grumach ${ }^{33}$
}

Received: 28 February 2021 / Accepted: 12 May 2021 / Published online: 23 June 2021

(c) The Author(s), under exclusive licence to Springer Science+Business Media, LLC, part of Springer Nature 2021

\begin{abstract}
Purpose There is still scarce data on SARS-CoV-2 infection in patients with Inborn Errors of Immunity (IEI) and many unresolved questions. We aimed to describe the clinical outcome of SARS-CoV-2 infection in Brazilian IEI patients and identify factors influencing the infection.

Methods We did a cross-sectional, multicenter study that included patients of any age affected by IEI and SARS-CoV-2 infection. The variables studied were sex, age, type of IEI, comorbidities (number and type), treatment in use for IEI, clinical manifestations and severity of SARS-CoV-2 infection.

Results 121 patients were included: $55.4 \%$ female, ages from six months to 74 yo (median age $=25.1$ yo). Most patients had predominantly antibody deficiency $(n=53)$. The infection was mostly asymptomatic $(n=21)$ and mild $(n=66)$, and one child had multisystem inflammatory syndrome (MIS-C). We could not observe sex-related susceptibility, and there was a weak correlation between age and severity of infection. The number of comorbidities was higher in severe cases, particularly bronchiectasis and cardiopathy. There were no severe cases in hereditary angioedema patients. Six patients aged 2 to 74 years died, three of them with antibody deficiency.

Conclusion The outcome was mild in most patients, but the Case Fatality Ratio was higher than in the general population. However, the type of IEI was not a determining factor for severity, except for complement deficiencies linked to milder COVID-19. The severity of SARS-CoV-2 infection seems to be more related to older age, a higher number of comorbidities and type of comorbidities (bronchiectasis and cardiopathy).
\end{abstract}

Keywords Primary immunodeficiency $\cdot$ Inborn errors of immunity $\cdot$ Immunodeficiency $\cdot$ COVID-19 $\cdot$ SARS-CoV-2 . Coronavirus

\section{Introduction}

SARS-CoV-2 infections emerged by the end of 2019, and since March 2020, we have experienced a pandemic. Most

Ekaterini Simões Goudouris

egoudouris@gmail.com

Extended author information available on the last page of the article people (80\%) with COVID-19 have mild respiratory symptoms [1], particularly children that, in general, are asymptomatic or have mild symptoms [2]. The disease includes severe pulmonary involvement in approximately $14 \%$ of individuals, while critical illness involving respiratory failure, sepsis, or multiple organ failure affects $5 \%$ of patients [1]. The case fatality ratio (CFR) varies from 1 to $5 \%$ in most countries, and in Brazil, it is around 2.5\% [3]. 
Risk factors for severe COVID-19 include old age and a few medical conditions: cancer, chronic kidney disease, chronic obstructive pulmonary disease (COPD), Down syndrome, heart conditions, obesity, pregnancy, sickle cell disease, solid organ transplantation, smoking, and type 2 diabetes mellitus [4].

Inborn errors of immunity (IEI) or primary immunodeficiencies (PID) are a heterogeneous group of diseases including more than 430 different gene defects [5] that could relate to a lower or a higher risk of complications by SARS-CoV-2 infection. According to the identified immunological defect, a group of experts from the UK developed a document classifying the risk of severe infection by SARS$\mathrm{CoV}-2$. This document was based on previous knowledge about the behavior of various immunological defects toward viral infections [6]. However, the clinical experience with SARS-CoV-2 infections was just starting.

Case reports and case series have been published about IEI patients' clinical outcomes [7-21]. Still, there are little data reported on SARS-CoV-2 in IEI patients and many unanswered questions.

Brazil is the third country in the world in the number of cases of COVID-19 and the second in the number of deaths and has health policies and socio-demographic characteristics differing from other countries reporting about patients with IEI and SARS-CoV-2 infection [22]. In this study we propose to describe the clinical development of SARS-CoV-2 infection in IEI Brazilian patients and to identify factors that influence the outcome.

\section{Methods}

We developed a cross-sectional, multicenter study, following STROBE statement including reference centers for IEI and hematopoietic stem cell transplantation (HSCT). The inclusion criteria were patients of any age diagnosed with an IEI according to the criteria used by the ESID registry [23] and confirmed diagnosis of SARS-CoV-2 infection by PCR and/or serology and/or point-of-care tests or presenting typical symptoms and/or imaging tests and history of contact with a confirmed case of SARS-CoV-2 infection. Patients with typical clinical manifestations or manifestations compatible with SARS-CoV-2 infection who did not have typical imaging and/or history of contact with confirmed cases of infection by this virus were excluded.

The following variables were assessed: sex, age, type of IEI, comorbidities (number and type), and the treatment in use before SARS-CoV-2 infection diagnosis and clinical manifestations of the infection. The severity of SARSCoV-2 infection was defined by the researchers, following NIH criteria [24], as asymptomatic, mild, moderate, severe, and critical. Type of IEI was defined according to the 2019 IUIS classification tables [5]. Case fatality ratio was calculated according to WHO scientific brief [25].

The data were inserted in IBM® SPSS Statistics (version 26) spreadsheet. Descriptive and statistical inference tools were used to analyze the correlation between categorical and numerical variables, with a significant $p$ value $\leq 0.05$. We performed correlations between variables: sex, median age, group of IEI, number and type of comorbidities, medications in use before infection $\times$ severity of SARS-CoV-2 infection; the number of comorbidities $\times$ age group; and type of clinical manifestation $\times$ severity of COVID-19 in different age groups. For correlation between ordinal variables, we used Kendall tau-b correlation coefficient and Gamma measure of association. For correlation between nominal/ordinal variables, we used Lambda measure of association and Cramer's V coefficient. Whenever possible, Fisher's test was used to assess significance. When not possible (by limitations of the software used), the Monte Carlo method was applied. Kruskal-Wallis test was used to compare numerical variables with different levels of SARS-CoV-2 infection severity.

The project was approved by the Research Ethics Committee (CAAE 31,264,220.0.1001.5264). Patients and/or their relatives signed a consent form to participate in the study.

\section{Results}

We collected data from 121 patients diagnosed with IEI and infected by SARS-CoV-2 between March and December 2020. RT-PCR tests confirmed the diagnosis of SARS-CoV-2 infection from nasopharyngeal or nasal swab in 82 patients (67.8\%); using RT-PCR and serology, in three patients $(2.5 \%)$; using serology only in 22 patients (18.2\%); and only by point-of-care test, in three patients $(2.5 \%)$, totaling $110(90.9 \%)$ patients. The other 11 patients $(9.1 \%)$ were included since they presented typical clinical manifestations of SARS-CoV-2 infection and/or typical imaging tests and history of contact with confirmed cases. No reinfections were reported during the study period.

Patients' ages ranged from 6 months to 74 years old (median age of 25.1 years). Age distribution was: $\leq 18$ years old, 57 patients $(47.1 \%) ; 19-59$ years old, 60 patients $(49.6 \%)$; and $\geq 60$ years old, four $(3.3 \%)$ patients. Sixty-seven patients were female (55.4\%). Thirteen patients with hereditary angioedema were included in Grumach et al. [26], four patients (two with familial Mediterranean fever and two with CVID) were already reported in Meyts's study [14], and another CVID patient 
was previously reported [20] (these patients are highlighted in the supplementary material).

Most patients were diagnosed with predominantly antibody deficiencies $(n=53 / 43.8 \%)$ and complement deficiencies $(n=25 / 20.7 \%)$. The distribution of cases according to the IEI classification group is shown in Fig. 1A.

Before SARS-CoV-2 infection, 49/121 (40.5\%) patients were under regular human immunoglobulin (IG) replacement, either intravenously $(89.8 \%)$ or subcutaneously (10.2\%). Chemoprophylaxis was used by $31 / 121$ (25.6\%) patients, and $11 / 121(9.1 \%)$ were using azithromycin. The use of immunosuppressors was reported in $11.6 \%(n=14)$, one of them for the hemophagocytic syndrome, the other for lymphoma, and the rest for autoimmune disorders. Other drugs included androgens in $8.3 \%(\mathrm{n}=10)$ and "immunomodulators" (colchicine or hydroxychloroquine) in $6.8 \%$ $(\mathrm{n}=8)$.

Comorbidities were absent in 70 patients $(57.8 \%)$; at least one comorbidity was observed in 37 patients (30.5\%); two comorbidities in 10 patients $(8.3 \%)$; and three or more comorbidities in four (3.3\%). Lung diseases were the most frequent comorbidities $(\mathrm{n}=34): 15.7 \%$ presented bronchiectasis $(n=19) ; 7.4 \%$, asthma $(n=9)$; and $5 \%$, other lung diseases $(n=6)$. Systemic arterial hypertension affected $11.6 \%$ $(\mathrm{n}=14)$; obesity, $8.3 \%(\mathrm{n}=10)$; overweight, $1.7 \%(\mathrm{n}=2)$; gastrointestinal disorders, $5.7 \%(\mathrm{n}=8)$; surgically corrected congenital heart diseases, $2.5 \%(n=3)$; Down syndrome,

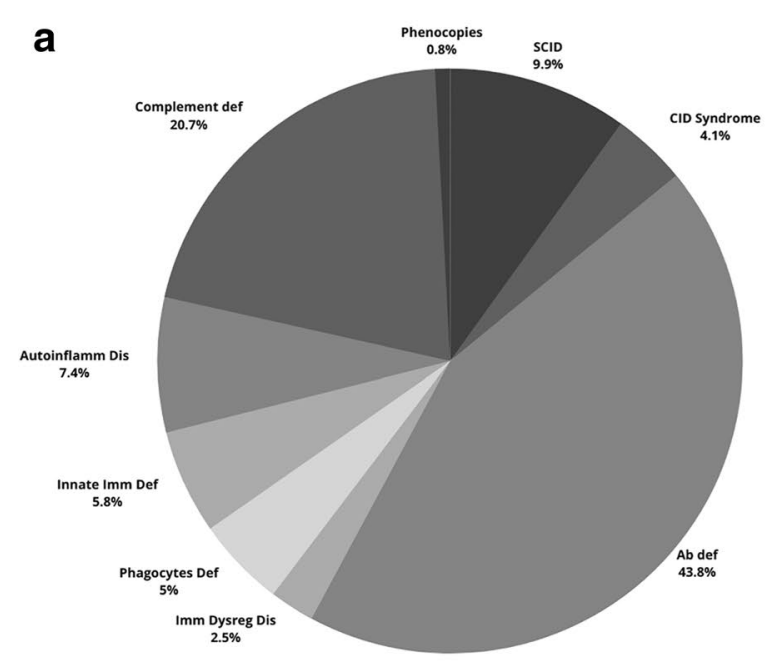

Fig. 1 A Distribution of IEI groups composed of 121 patients with a diagnosis of SARS-CoV-2 infection. Predominantly antibody deficiencies $n=53$; complement deficiencies $n=25$; combined $T$ and $B$ cell deficiencies $n=12$ (seven of them transplanted); autoinflammatory diseases $n=9$; innate immunity defects $n=7$, phagocyte defects $\mathrm{n}=6$ (one of them transplanted); combined $\mathrm{T}$ and $\mathrm{B}$ cell deficiencies associated with syndromes $\mathrm{n}=5$ (one of them transplanted); immune
2.5\% ( $\mathrm{n}=3)$; type II diabetes mellitus, $3.3 \%(\mathrm{n}=4)$; and type I diabetes mellitus, $1.7 \%(\mathrm{n}=2)$. One patient was pregnant.

A hundred and twenty IEI patients presented acute SARS-CoV-2 infection where 21 were classified as asymptomatic and 99 were symptomatic (i.e., had COVID-19) (Fig. 1B). One patient presented MIS-C. From 100 symptomatic patients (99 diagnosed with COVID-19 and one patient with MIS-C), 35 patients were hospitalized and 94 recovered. The 21 asymptomatic patients underwent the SARS-CoV-2 RT-PCR test either because of hospitalization for another reason than COVID-19 or due to a history of contact with a positive case.

There was no correlation between sex and severity of the infection, neither in general (Kendall's tau-b 0.095, $\mathrm{p}=0.265$ Fisher's test) nor in the group of children/adolescents (Kendall's tau-b 0.052, $\mathrm{p}=0.693$ Fisher's test) or the group of adults (Kendall's tau-b 0.032, p=0.794 Fisher's test).

A significant difference in the median age among the five levels of severity of SARS-CoV-2 infection was identified (Kruskal-Wallis test $\mathrm{p}=0.004$ ). The asymptomatic group median age was lower than for the other levels of severity. However, a significant difference was detected between asymptomatic and mild cases and also severe cases but not between asymptomatic and critical or moderate cases (age standard deviation for critical and moderate cases was higher). No significant difference was identified between

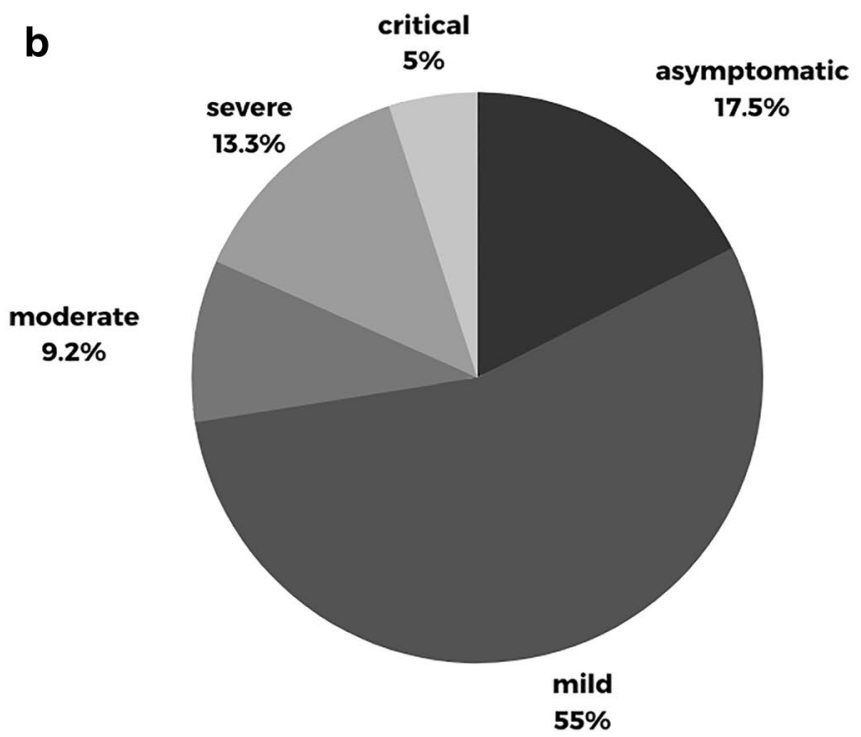

dysregulation diseases $n=3$ (one of them transplanted); bone marrow failure $n=0$; and phenocopies of immunodeficiencies $n=1$. B Severity of acute SARS-CoV-2 infection in 120 patients: asymptomatic $n=21$; mild $n=66$, moderate $n=11$, severe $n=16$, critical $n=6$. Def - deficiencies; SCID - severe combined immunodeficiency; CID combined immunodeficiency; Ab - antibody; Imm - immune; Dysreg - Dysregulation; Dis - diseases; Autoinflam - autoinflammatory 
mild, moderate, severe, and critical cases median ages (Fig. 2).

A clear correlation between the IEI group and the severity of infection was not identified (Gamma 0.001, $\mathrm{p}=0.992$; Kendall's tau-b 0.001, $\mathrm{p}=0.992$ Monte Carlo method). Complement deficiencies were the second most common IEI, and no report of severe cases was observed. On the other hand, in the phenocopy group, a single patient reported died. The distribution of SARS-CoV-2 infections severity in the different types of IEI is described in Fig. 3.

There was a weak correlation between the use of immunoglobulin and the higher severity of SARS-CoV-2 infection (Cramer's V 0.345, $\mathrm{p}=0.005$ Fisher's test) and between the use of immunosuppressors and lower severity of SARSCoV-2 infection (Cramer's V 0.304, $p=0.029$ Fisher's test). $\mathrm{Six} / 14$ patients who were in use of immunosuppressors were asymptomatic, 4/14 had mild COVID-19, and one had a critical COVID-19.

A difference in the number of comorbidities concerning the severity of SARS-CoV-2 infection was observed (Kruskal-Wallis test $\mathrm{p}<0.001$ ), but there was a difference only between asymptomatic + mild + moderate cases and severe + critical cases. In addition, there was a difference between the number of comorbidities and the age group of patients (Kruskal-Wallis test $p=0.008$ ), but only between $\leq 18$-year-old $+19-59$-year-old groups and $\geq 60$ years old, but not between $\leq 18$ years old and 19-59-year-old groups.

The correlation between types of comorbidities presented by the patients and the severity of SARS-CoV-2 infection showed a weak correlation between the presence of bronchiectasis (Cramer's V 0.365, $\mathrm{p}=0.004$ Fisher's test) and cardiopathy (Cramer's V 0.302, $\mathrm{p}=0.047$ Fisher's test) and higher severity. The pregnant patient, who had an autoinflammatory disease (CAPS-NLRP12 mutation) presented as mild COVID-19.

Fever was the most common symptom, reported in 66/99 (66.7\%) patients with COVID-19. Other frequent symptoms were cough in $56.6 \%(n=56)$, upper airway symptoms (sore throat, nasal congestion, coryza) in 53.3\% $(\mathrm{n}=53)$, hypoor anosmia in $38.4 \%(n=380$, headache in $32.2 \%(n=32)$, dyspnea in $29.3 \%(n=29)$, dys- or ageusia in $29.3 \%(n=29)$, diarrhea in $23.2 \%(n=23)$, fatigue in $8.1 \%(n=8)$, chest pain in $6.1 \%(\mathrm{n}=6)$, abdominal pain in $5.1 \%(\mathrm{n}=5)$, vomiting in $4 \%(n=4)$, and pericarditis in $2 \%(n=2)$. Other clinical manifestations have been described in only one case each: conjunctivitis, ocular and nasal burning, parotitis, cholestasis, and oral ulcers. Five patients with hereditary angioedema ( $35.7 \%$ of the 24 patients) presented edema attacks: four with subcutaneous edema (one also with abdominal crisis) and one with laryngeal edema. Five patients presented cutaneous rash and one of them had a previous diagnosis of CAPS-NLRP3 and presented a diffuse cutaneous maculopapular rash that on skin biopsy demonstrated lymphocytic vasculitis, probably related to the viral infection. Bacterial pneumonia was a secondary diagnosis in 11 cases and sepsis in two, but with no identification of an infectious agent.

A 6-year-old girl with a possible innate immunity defect with susceptibility to bacterial infections (genetic testing in progress) presented fever, skin rash, pleural and pericardial effusion, ascites, and nonspecific pulmonary infiltrate with dragged evolution. SARS-CoV-2 RT-PCR by swab was three times negative, and serology (IgG $>100 \mathrm{AU} / \mathrm{mL})$ was also positive three times. In addition, cytokine dosage showed a significant increase of IL-10 and a lower increase
Fig. 2 Median age across severity of SARS-CoV-2 infection $(n=120)$

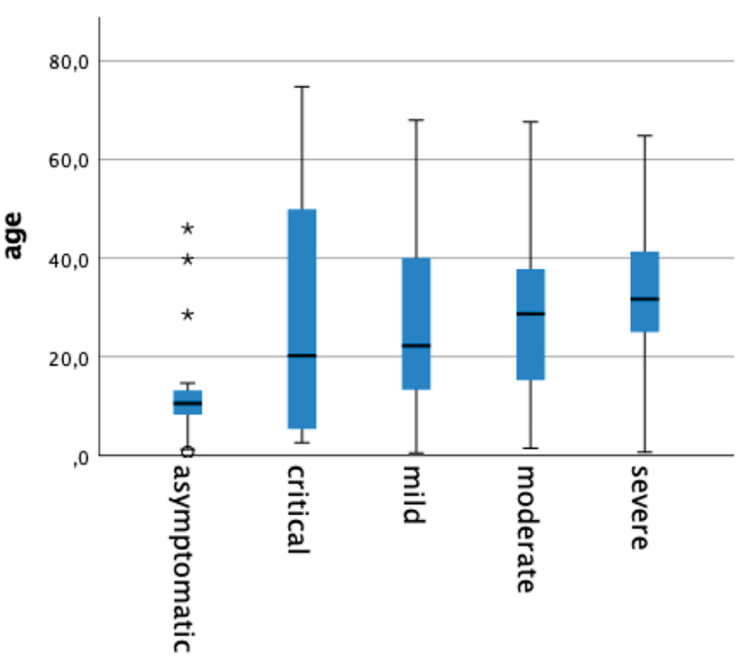

Severity Infection

\begin{tabular}{|l|l|}
\hline Severity Grade median age & P value \\
\hline Asymptomatic-symptomatic & $0.000^{*}$ \\
\hline Asymptomatic-critical & 0.907 \\
\hline Asymptomatic-mild & $0.005^{*}$ \\
\hline Asymptomatic-moderate & 0.162 \\
\hline Asymptomatic-severe & $0.006^{*}$ \\
\hline Critical-mild & 1.000 \\
\hline Critical-moderate & 1.000 \\
\hline Critical-severe & 1.000 \\
\hline Mild-moderate & 1.000 \\
\hline Mild-severe & 1.000 \\
\hline Moderate-severe & 1.000 \\
\hline
\end{tabular}




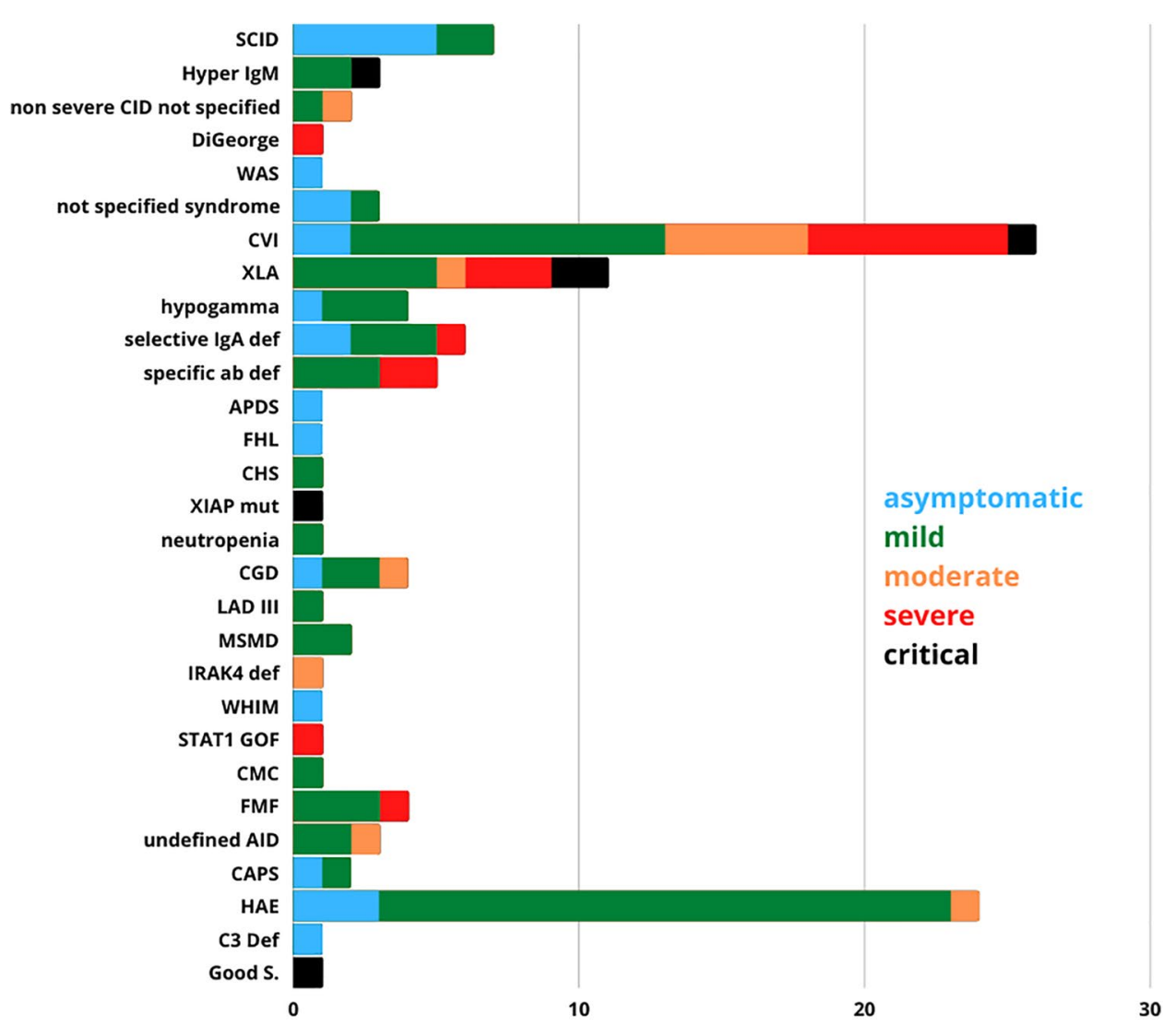

Fig. 3 Severity of SARS-CoV-2 infection in 120 patients with various IEI (excluding patient with MIS-C). SCID - severe combined immunodeficiency (seven post-HSCT); CID - combined immunodeficiency; WAS - Wiskott-Aldrich syndrome (one post-HSCT); CVID - common variable immunodeficiency; XLA - X-linked agammaglobulinemia; APDS - activated p1108 Syndrome (PI3KCD); FHL - familial hemophagocytic lymphohistiocytosis; CHS - ChediakHigashi syndrome; XIAP - one post-HSCT; CGD - chronic granu-

in IL-6, diagnosed as a systemic inflammatory condition after infection by SARS-CoV-2 (MIS-C).

The correlation between clinical manifestations and severity of COVID-19 in patients $\leq 18$ years showed a moderate correlation between rash (Cramer's V 0.598, $\mathrm{p}=0.024$ Fisher's test) and vomiting (Cramer's V 0.598, $\mathrm{p}=0.024$ Fisher's test) with higher severity. These symptoms were identified only in the $\leq 18$-year-old group. Clinical manifestations and severity of COVID-19 in patients $\geq 19$ years old showed a correlation between cough (weak, Cramer's V 0.337, $\mathrm{p}=0.027$ Fisher's test) and dyspnea (moderate-Cramer's V 0.456, p =0.003 Fisher's test) both associated with higher severity.

Ten patients with SCID $(n=7)$, LAD type III $(n=1)$, WAS $(n=1)$, and XIAP mutation $(n=1)$ had SARSCoV-2 infection after hematopoietic stem cell transplant (HSCT) (see Table 1). The majority $(n=7)$ were detected after 100 days of transplantation, and of these, four were lomatous disease (three males, probably XL form, and one female CYBA); LAD - leukocyte adhesion deficiency (one post- HSCT); MSMD - Mendelian susceptibility to mycobacterial infections (one IFNGR1, one IFNGR2); WHIM - warts, hypogammaglobulinemia, infections, myelokathexis; $\mathrm{CMC}$ - chronic mucocutaneous candidiasis (probably IL-17 defect); FMF - familiar Mediterranean fever; AID - autoinflammatory disease; CAPS - cryopyrin-associated periodic syndrome; HAE - hereditary angioedema

asymptomatic and three had mild COVID-19. Among the three patients with SARS-CoV-2 infection within the first 100 days of HSCT, two were asymptomatic. A third one was a patient with XIAP mutation presenting mild COVID19 symptoms (fever and rash with positive RT-PCR) on the sixth day after a haploidentical HSCT. He developed multiple complications related to poor graft function and venoocclusive disease and died due to a fungal infection four months after being hospitalized most of the time.

Patients classified as critical COVID-19 died. All of them presented severe pulmonary manifestation with sepsis and/or multiple organ failure. Four were male, ranging from two to 74 years, with a median age of 20.2 years. Two patients were diagnosed with X-linked agammaglobulinemia, one with common variable immunodeficiency, one with hyper IgM syndrome (CD40L defect), and one with Good syndrome.

The patient with hyper IgM syndrome was a 15-yearold boy with no comorbidities and a severe inflammatory 
manifestation of COVID-19. One of the deceased patients with a diagnosis of $\mathrm{X}$-linked agammaglobulinemia was an obese child. The other patient with X-linked agammaglobulinemia was a young adult with bronchiectasis, asthma, hypertension, and overweight. A year younger, this patient's brother, also diagnosed with X-linked agammaglobulinemia, obese, and no other comorbidities, evolved with COVID19 classified as moderate and recovered well. The deceased patient with common variable immunodeficiency presented bronchiectasis and arterial hypertension. The patient with Good syndrome (74 years old) who had myasthenia gravis went through adrenalectomy and pulmonary lobectomy previously.

Case fatality ratio and inpatient mortality were $5 \%$ and $17.1 \%$, respectively, among all 121 patients. CFR and inpatient mortality according to IEI classification were, respectively: antibody deficiencies $(n=53) 6.38 \%$ and $17.6 \%$; non-severe combined T/B cells deficiency $(n=5) 20 \%$ and $50 \%$, immune dysregulation $(n=3) 50 \%$ and $50 \%$; and phenocopies $(\mathrm{n}=1) 100 \%$ and $100 \%$. CFR in $\leq 18$-year-old group $(n=57)$ was $3.5 \%$; in $19-59$ years old $(n=60), 5 \%$ and in $\geq 60$ years old $(n=4), 25 \%$.

Data from the 121 patients of the study are detailed in supplemental file 1 .

Table 1 Characteristics and evolution of ten patients with IEI and SARS-CoV-2 infection post-hematopoietic stem cell transplantation

\begin{tabular}{|c|c|c|c|c|c|}
\hline IEI & Sex & Age & $\begin{array}{l}\text { Time post } \\
\text { HSCT }\end{array}$ & $\begin{array}{l}\text { Severity } \\
\text { SARS-CoV-2 } \\
\text { infection }\end{array}$ & Outcome \\
\hline SCID & M & 13 y.o & $>100 \mathrm{~d}$ & $\begin{array}{l}\text { Asympto- } \\
\text { matic }\end{array}$ & - \\
\hline SCID & M & 8 у.о & $>100 \mathrm{~d}$ & $\begin{array}{l}\text { Asympto- } \\
\text { matic }\end{array}$ & - \\
\hline SCID & M & 6 у.о & $>100 \mathrm{~d}$ & $\begin{array}{l}\text { Asympto- } \\
\text { matic }\end{array}$ & - \\
\hline SCID & $\mathrm{M}$ & 3 у.о & $>100 \mathrm{~d}$ & Mild & Recovered \\
\hline SCID & $\mathrm{F}$ & 2 y.o & $>100 \mathrm{~d}$ & $\begin{array}{l}\text { Asympto- } \\
\text { matic }\end{array}$ & - \\
\hline SCID & $\mathrm{F}$ & 2 y.o & $>100 \mathrm{~d}$ & Mild & Recovered \\
\hline SCID & M & 8 months & $73 \mathrm{~d}$ & $\begin{array}{l}\text { Asympto- } \\
\text { matic }\end{array}$ & - \\
\hline WAS & M & 12 y.o & $48 \mathrm{~d}$ & $\begin{array}{l}\text { Asympto- } \\
\text { matic }\end{array}$ & - \\
\hline LAD III & $\mathrm{F}$ & 12 y.o & $>100 \mathrm{~d}$ & Mild & Recovered \\
\hline XIAP & M & 2 у.о & $6 \mathrm{~d}$ & Mild & Death* \\
\hline
\end{tabular}

*due to complications related to HSCT and uncertain contribution of SARS-CoV-2 infection

\section{Discussion}

The restricted knowledge about the immunopathology of SARS-CoV-2 infection for IEI patients raised the question about the clinical impact of COVID-19 and the risk involved for these patients [27]. As already mentioned, several case reports were previously published $[7-13,15]$, as well as two large series: 94 IEI patients in Meyts et al. study, from ESID [14], and 60 IEI patients and 33 secondary immunodeficient patients from Shields et al. study [16], in the UK.

In our group of 121 IEI patients with SARS-CoV-2 infection, females were more frequent (55.4\%), unlike Meyts et al. and Marcus et al.'s studies [14, 21], however similar to the 60 IEI patients from Shields et al. [16] report. Our group of patients was younger than the other series of patients.

Predominantly antibody deficiencies represented the most frequent IEI among our patients (43.8\%) as described in other series $[14,16,21]$, but in a lower proportion, particularly in comparison to Shields' group (76.7\%). In our series, the second most frequent IEI was complement deficiencies (20.7\%), absent from Meyts's group and in lower numbers in Shields' group (6.7\%), due to different structured groups of specialists registering HAE patients.

Most of our patients had no comorbidities, unlike Meyts's and Shields' samples, mainly having lung disease comorbidity. This characteristic is probably related to the younger age of our patients. Most of our patients were symptomatic $(\mathrm{n}=100 ; 82.6 \%)$. In particular, Brazil has not implemented mass testing, and the SARS-CoV-2 tests are usually performed in hospitalized patients, especially in the public health system. Since patients with IEI have not been routinely tested or tested whenever they had a history of contact or symptoms, it is impossible to affirm that patients with IEI have more frequent symptoms related to SARS-CoV-2 infection than the general population. We have a younger group of patients, and, still, the percentage of asymptomatic patients (17.4\%) was slightly above that presented in the ESID series (11\%) [14]. In addition, most symptomatic patients presented mild cases of COVID-19, as reported by Meyts et al. [14] and by Marcus et al. [21]. The study by Marcus et al. presented a series of 20 patients between 4 months and 60 years of age, $60 \%$ male, $80 \%$ having alterations in the production of antibodies, and seven of them with combined defects of $\mathrm{T}$ and $\mathrm{B}$ cells (one of them 20 years after hematopoietic stem cell transplantation). No deaths were reported, none of them required hospitalization because of SARS-CoV-2 infection, and seven of them (including one 22q11.2 deletion, one CGD, two combined immunodeficiency, one XLA, and one CVID) were asymptomatic. [21]

The symptoms most frequently described in our 99 patients with COVID-19 were similar to those described in other series of patients with or without IEI [14, 28-31]. 
Unlike published data, we have not identified headache, olfactory disorders, or taste disorders as markers of milder COVID-19 [32, 33]. Cough and dyspnea have been described before as predictors of severity in adults [34-36]. However, cutaneous rash and vomiting have not been described before as predictors of severity in children [37-39].

We report one case with a possible innate immunity defect with susceptibility to bacterial infections and MIS-C diagnosis based on previously reported differences in relation to the inflammatory phase of COVID-19 [40]. There are two previous MIS-C reports in patients with IEI: a patient with SOCS1 haploinsufficiency, a disease characterized by early-onset autoimmunity due to reduced JAK-STAT pathway inhibition [41] and a patient with IFNGR2 defect, reported in Meyts et al. study [14]. Another patient in our series, with confirmed IRAK4 deficiency, presented a severe inflammatory condition related to COVID-19, ratifying the role of innate immunity defects in the pathogenesis of severe SARS-CoV-2 infection [42].

We observed no sex susceptibility difference for severe SARS-CoV-2 infections in the group $\geq 19$ years old nor in the $\leq 18$-year-old group. No sex difference for COVID-19 susceptibility has been observed in children [43], although it is frequently reported in adults [44, 45]. It is important to note that HAE was the second most common IEI in our group of patients, more frequent in females due to hormones' influence and related to less severe form of COVID-19. Moreover, we found no male predominance for severe cases.

Young patients had severe cases in our series. Also, we did not identify protection against severe COVID-19 among patients with antibody deficiencies, as was shown by Meyts's [14], Ho's [12], and Shields's [16], and contrary to what was reported at the beginning of the pandemic $[17,46]$ and by Marcus et al. [21]. Five (83.3\%) deceased patients were $\leq 59$ years old, and three $(50 \%)$ of them had antibody deficiencies. The results of our analyses suggest that the presence of comorbidities, particularly the presence of bronchiectasis, is responsible for this finding. In addition, we can hypothesize that the production of antibodies is not irrelevant in the immune response to SARS-CoV-2. It is essential to report that only one of our patients (CVID, previously published) received convalescent plasma (not widely available in Brazil), described as effective in some patients with antibody deficiencies $[13,20,47]$. We ratified findings from previous publications $[26,48]$ on the prevalence of mild conditions among patients with complement deficiencies, and more than a third presented edema attacks. Edema attacks in $31 \%$ of HAE patients during SARS-CoV-2 infections have also been described recently, but with two cases of severe infections [49].

The outcome of SARS-CoV-2 infections was less severe in patients submitted to HSCT in our group, particularly those having the disease more than 100 days post-transplantation, as it was expected. However, even the patients in our series who had the infection before 100 days post-transplantation had better outcomes than reported in a group of 318 HSCT recipients, including only four IEI patients [50].

The use of immunoglobulin was related to severe SARSCoV-2 infection. It is important to note that $14 / 19$ patients with bronchiectasis received IG, a possible explanation for this finding. On the other hand, immunosuppressors, a risk factor reported in some publications $[4,27]$ and a non-interfering factor in others [51], were identified by our group as a possible protective factor against severe cases, probably by reducing the inflammatory process. The use of androgens was not related to higher severity, suggesting that male hormones' proposed interference in higher severity of COVID19 should be further investigated [52].

A correlation between the number of comorbidities and increased severity of COVID-19 was detected, but not between $<18$-year-old and 19-59-year-old groups. In addition, we had only four patients in this oldest group. Probably that is the reason we have not identified a strong correlation between age and severity. The presence of bronchiectasis and cardiopathy showed a correlation with higher severity of SARS-CoV-2 infection, as shown by Shields et al. [16]. These observations suggest that comorbidities are a determinant factor for SARS-CoV-2 infection severity in our series of patients.

We registered 6 deaths out of 121 cases, a lower percentage (5\%) than the $10 \%$ reported by Meyts et al. [14], probably because our group is younger, with fewer comorbidities and a female predominance. CFR in our group of antibody deficiency patients $(6.38 \%)$ is much lower than in Ho et al. [12] series (25\%), composed of adults only and predominantly males. CFR (5\%) and inpatient mortality (17.1\%) in our group were also considerably lower than the values reported by Shields et al. [16] (31.6\% and $37.5 \%$, respectively), most likely due to the lower age of our patients and fewer comorbidities, as both series of patients were female-biased. However, our CFR values (5\%) are considerably higher than those described in Brazil's general population (2.5\%) [3].

Our study has some limitations. Asymptomatic patients could not be detected as there was no systematic testing in our population. Also, the under-representation of several IEI diseases in our series and the low number of patients and study's descriptive methodology compromise the statistical analysis, preventing, therefore, precise statements about the relationship between the severity of COVID-19, all types of IEI and other variables. The pandemic's evolution and the increasing number of IEI patients infected by SARS-CoV-2 may change our punctual observation. Nevertheless, until now, the series reported here represents one of the largest studying IEI and SARS-CoV-2 infection. 
In conclusion, the disease outcome was mild in most patients with IEI, but CFR was higher than in the general population. Regarding HAE, SARS-CoV-2 represents a trigger factor for edema attacks. The severity of SARSCoV-2 infection in IEI patients seems to be related to older age, especially to a higher number of comorbidities and types of comorbidities (bronchiectasis and cardiopathy). We do not know how the pandemic's evolution will develop, despite the enormous expectation about the start of active immunization. Therefore, we consider it relevant to keep studying different aspects of SARS-CoV-2 infection in patients with IEI.

Abbreviations COVID-19; Coronavirus disease 2019: $C F R$; Case fatality ratio: $C O P D$; Chronic obstructive pulmonary disease: $C V I D$; Common variable immunodeficiency: ESID; European Society for Immunodeficiencies: $H A E$; Hereditary angioedema: HSCT; Hematopoietic stem cell transplant: IEI; Inborn errors of immunity: IFR; Infection fatality ratio: $I G$; Immunoglobulin: IUIS; International Union of Immunological Societies: $M I S-C$; Multisystem inflammatory syndrome in children: $N I H$; National Institutes of Health: PID; Primary immunodeficiencies: $R T-P C R$; Reverse transcription-polymerase chain reaction: $S A R S-$ $\mathrm{CoV}$-2; Severe acute respiratory syndrome coronavirus 2: $U K$; United Kingdom

Supplementary Information The online version contains supplementary material available at https://doi.org/10.1007/s10875-021-01066-8.

Acknowledgements The authors would like to acknowledge all patients and their families, who allowed the data to be used in this publication, particularly to those who tragically lost their loved ones, and to Jeffrey Modell Foundation (not-for-profit institution) for funding for the preparation of the article.

Author Contribution All authors have contributed substantively and intellectually to this paper. The contributions of each author are described in the cover letter.

Funding This study received Jeffrey Modell Foundation (not-for-profit institution) funding for the preparation of the manuscript.

Data Availability Data of all patients are described in the supplementary excel file.

Code Availability IBM® SPSS Statistics (version 26).

\section{Declarations}

Ethics approval The project was approved by the Research Ethics Committee (CAAE 31264220.0.1001.5264).
Consent to participate Patients and/or their relatives signed a consent form to participate in the study.

Consent for publication Not applicable.

Conflicts of interest The authors declare no competing interests.

\section{References}

1. Wu Z, McGoogan JM. Characteristics of and important lessons from the coronavirus disease 2019 (COVID-19) outbreak in China: summary of a report of 72314 cases from the Chinese Center for Disease Control and Prevention. JAMA. 2020;323(13):1239-42.

2. Bixler D, Miller AD, Mattison CP, Taylor B, Komatsu K, Peterson Pompa X, et al. SARS-CoV-2-associated deaths among persons aged $<21$ years - United States, February 12-July 31, 2020. MMWR Morb Mortal Wkly Rep. 2020;69(37):1324-9.

3. Dong E, Du H, Gardner L. An interactive web-based dashboard to track COVID-19 in real time. Lancet Infect Dis. 2020;20(5):533-4.

4. National Center for Immunization and Respiratory Diseases (NCIRD), Division of Viral Diseases. People with Certain Medical Conditions. CDC; 2020 [updated Dec. 29, 2020]. Available at: https://www.cdc.gov/coronavirus/2019-ncov/need-extra-preca utions/people-with-medical-conditions.html?CDC_AA_refVal= https $\% 3 \mathrm{~A} \% 2 \mathrm{~F} \% 2 \mathrm{Fwww} . c d c$.gov $\% 2$ Fcoronavirus $\% 2 \mathrm{~F} 2019$ ncov\%2Fneed-extra-precautions $\% 2$ Fgroups-at-higher-risk.html. Accessed 15 Jan 2020.

5. Tangye SG, Al-Herz W, Bousfiha A, Chatila T, CunninghamRundles C, Etzioni A, et al. Human inborn errors of immunity: 2019 update on the classification from the International Union of Immunological Societies Expert Committee. J Clin Immunol. 2020;40(1):24-64.

6. United Kingdom Primary Immunodeficiency Network (UKPIN). Advice for healthcare professionals looking after patients with immunodeficiency regarding COVID-19. UKPIN; 2020 [updated March 24, 2020]. Available at: https://www.ukpin.org.uk/docs/ default-source/default-document-library/ukpin_risk_stratifica tion_covid19_finalac6baa9cd4eb6fe9b40eff00005026c1.pdf Accessed 15 Jan 2020.

7. Ahanchian H, Moazzen N, Faroughi MSD, Khalighi N, Khoshkhui M, Aelami MH, et al. COVID-19 in a child with primary specific antibody deficiency. Research Square.2020, https://onlinelibrary. wiley.com/doi/pdf/https://doi.org/10.1002/ccr3.3643

8. Aljaberi R, Wishah K. Positive outcome in a patient with coronavirus disease 2019 and common variable immunodeficiency after intravenous immunoglobulin. Ann Allergy Asthma Immunol. 2020;125(3):349-50.

9. Castano-Jaramillo LM, Yamazaki-Nakashimada MA, Scheffler Mendoza SC, Bustamante-Ogando JC, Espinosa-Padilla SE, Lugo Reyes SO. A male infant with COVID-19 in the context of ARPC1B deficiency. Pediatr Allergy Immunol. 2021;32(1):199-201.

10. Cohen B, Rubinstein R, Gans MD, Deng L, Eisenberg R, Rubinstein A. COVID-19 Infection in ten common variable immunodeficiency patients in New York city. J Allergy Clin Immunol In Practice. 2021;9(1):504-507.e1.

11. Fill L, Hadney L, Graven K, Persaud R, Hostoffer R. The clinical observation of a patient with common variable immunodeficiency diagnosed as having coronavirus disease 2019. Ann Allergy Asthma Immunol. 2020;125(1):112-4. 
12. Ho HE, Mathew S, Peluso MJ, Cunningham-Rundles C. Clinical outcomes and features of COVID-19 in patients with primary immunodeficiencies in New York City. J Allergy Clin Immunol In Practice. 2021;9(1):490-493.e2.

13. Jin H, Reed JC, Liu STH, Ho HE, Lopes JP, Ramsey NB, et al. Three patients with $\mathrm{X}$-linked agammaglobulinemia hospitalized for COVID-19 improved with convalescent plasma. J Allergy Clin Immunol Pract. 2020;8(10):3594-3596 e3.

14. Meyts I, Bucciol G, Quinti I, Neven B, Fischer A, Seoane E, et al. Coronavirus disease 2019 in patients with inborn errors of immunity: an international study. J Allergy Clin Immunol. 2020. https://doi.org/10.1016/j.jaci.2020.09.010.

15. Mullur J, Wang A, Feldweg A. A fatal case of coronavirus disease 2019 in a patient with common variable immunodeficiency. Ann Allergy Asthma Immunol. 2021;126(1):90-2.

16. Shields AM, Burns SO, Savic S, Richter AG, consortium UPC-. COVID-19 in patients with primary and secondary immunodeficiency: the United Kingdom experience. J Allergy Clin Immunol. 2020. https://doi.org/10.1016/j.jaci.2020.12.620

17. Soresina A, Moratto D, Chiarini M, Paolillo C, Baresi G, Foca $\mathrm{E}$, et al. Two X-linked agammaglobulinemia patients develop pneumonia as COVID-19 manifestation but recover. Pediatr Allergy Immunol. 2020;31(5):565-9.

18. Van Damme KFA, Tavernier S, Van Roy N, De Leeuw E, Declercq J, Bosteels C, et al. Case report: convalescent plasma, a targeted therapy for patients with CVIDD and severe COVID19. Front Immunol. 2020. https://doi.org/10.3389/fimmu.2020. 596761.

19. Fallatah E, Chang Y, Calderon J, Trujillo VH. DiGeorge syndrome and COVID-19 in two pediatric patients. J Allergy Clin Immunol. 2021;147(2):AB66

20. Ribeiro LC, Benites BD, Ulaf RG, Nunes TA, Costa-Lima C, Addas-Carvalho M, et al. Rapid clinical recovery of a SARSCoV-2 infected common variable immunodeficiency patient following the infusion of COVID-19 convalescent plasma. Allergy Asthma Clin Immunol. 2021;17(1):14.

21. Marcus N, Frizinsky S, Hagin D, Ovadia A, Hanna S, Farkash M, et al. Minor clinical impact of COVID-19 pandemic on patients with primary immunodeficiency in Israel. Front Immunol. 2020;11:614086

22. World Health Organization. WHO coronavirus disease (COVID19) Dashboard (web). https://covid19.who.int: WHO; 2020. Available at https://covid19.who.int/ Accessed Jan15 2020.

23. Seidel MG, Kindle G, Gathmann B, Quinti I, Buckland M, van Montfrans J, et al. The European Society for Immunodeficiencies (ESID) registry working definitions for the clinical diagnosis of inborn errors of Immunity. J Allergy Clin Immunol In Practice. 2019;7(6):1763-70.

24. National Institutes of Heakth (NIH). Clinical spectrum of SARSCoV-2 infection [updated Dec 17 2020]. Available at: https:// www.covid19treatmentguidelines.nih.gov/overview/clinical-spect $\mathrm{rum} /$. Accessed 15 Jan 2020.

25. World Health Organization. Estimating mortality from COVID19. 2020. Report No.: WHO-2019-nCoV-Sci_Brief-Mortality-2020.1. Available at: https://apps.who.int/iris/bitstream/ handle/10665/333642/WHO-2019-nCoV-Sci_Brief-Mortality2020.1-eng.pdf? sequence $=1 \&$ isAllowed $=y$ Accessed 15 Jan 2020.

26. Grumach AS, Goudouris E, Dortas Junior S, Marcelino FC, Alonso MLO, Martins RO, et al. COVID-19 affecting hereditary angioedema patients with and without $\mathrm{C} 1$ inhibitor deficiency. $\mathrm{J}$ Allergy Clin Immunol Pract. 2021;9(1):508-10.

27. Gao Y, Chen Y, Liu M, Shi S, Tian J. Impacts of immunosuppression and immunodeficiency on COVID-19: a systematic review and meta-analysis. J Infect. 2020;81(2):e93-5.
28. Guan WJ, Ni ZY, Hu Y, Liang WH, Ou CQ, He JX, et al. Clinical characteristics of coronavirus disease 2019 in China. N Engl J Med. 2020;382(18):1708-20.

29. Aggarwal S, Garcia-Telles N, Aggarwal G, Lavie C, Lippi G, Henry BM. Clinical features, laboratory characteristics, and outcomes of patients hospitalized with coronavirus disease 2019 (COVID-19): Early report from the United States. Diagnosis (Berl). 2020;7(2):91-6.

30. de Souza WM, Buss LF, Candido DDS, Carrera JP, Li S, Zarebski AE, et al. Epidemiological and clinical characteristics of the COVID-19 epidemic in Brazil. Nat Hum Behav. 2020;4(8):856-65.

31. Teich VD, Klajner S, Almeida FAS, Dantas ACB, Laselva $\mathrm{CR}$, Torritesi MG, et al. Epidemiologic and clinical features of patients with COVID-19 in Brazil. Einstein (Sao Paulo). 2020;18:eAO6022.

32. Gonzalez-Martinez A, Fanjul V, Ramos C, Serrano Ballesteros J, Bustamante M, Villa Marti A, et al. Headache during SARS$\mathrm{CoV}-2$ infection as an early symptom associated with a more benign course of disease: a case-control study. Eur J Neurol. 2021. https://doi.org/10.1111/ene.14718.

33. Sedaghat AR, Gengler I, Speth MM. Olfactory dysfunction: a highly prevalent symptom of COVID-19 with public health significance. Otolaryngol Head Neck Surg. 2020;163(1):12-5.

34. Barek MA, Aziz MA, Islam MS. Impact of age, sex, comorbidities and clinical symptoms on the severity of COVID-19 cases: a meta-analysis with 55 studies and 10014 cases. Heliyon. 2020. https://doi.org/10.1016/j.heliyon.2020.e05684.

35. Jain V, Yuan JM. Predictive symptoms and comorbidities for severe COVID-19 and intensive care unit admission: a systematic review and meta-analysis. Int J Public Health. 2020;65(5):533-46.

36. Zhang SY, Lian JS, Hu JH, Zhang XL, Lu YF, Cai H, et al. Clinical characteristics of different subtypes and risk factors for the severity of illness in patients with COVID-19 in Zhejiang, China. Infect Dis Poverty. 2020, https://idpjournal.biomedcentral.com/ articles/https://doi.org/10.1186/s40249-020-00710-6

37. Yasuhara J, Kuno T, Takagi H, Sumitomo N. Clinical characteristics of COVID-19 in children: a systematic review. Pediatr Pulmonol. 2020;55(10):2565-75.

38. Du H, Dong X, Zhang JJ, Cao YY, Akdis M, Huang PQ, et al. Clinical characteristics of 182 pediatric COVID-19 patients with different severities and allergic status. Allergy. 2020. https://doi. org/10.1111/all.14452.

39. Ghazal S, Litvinov IV, Aljahani N, Jfri A, Netchiporouk E. Cutaneous manifestations of coronavirus disease 2019 (COVID19) infection-what do we know so far? J Cutan Med Surg. 2020;24(4):416-7.

40. Diorio C, Henrickson SE, Vella LA, McNerney KO, Chase J, Burudpakdee C, et al. Multisystem inflammatory syndrome in children and COVID-19 are distinct presentations of SARSCoV-2. J Clin Invest. 2020;130(11):5967-75.

41. Lee PY, Platt CD, Weeks S, Grace RF, Maher G, Gauthier K, et al. Immune dysregulation and multisystem inflammatory syndrome in children (MIS-C) in individuals with haploinsufficiency of SOCS1. J Allergy Clin Immunol. 2020;146(5):1194-200 e1.

42. Zhang Q, Bastard P, Liu Z, Le Pen J, Moncada-Velez M, Chen J, et al. Inborn errors of type I IFN immunity in patients with lifethreatening COVID-19. Science. 2020;370(6515):eabd4570.

43. Dong Y, Mo X, Hu Y, Qi X, Jiang F, Jiang Z, et al. Epidemiology of COVID-19 among children in China. Pediatrics. 2020. https:// doi.org/10.1542/peds.2020-0702.

44. Jin JM, Bai P, He W, Wu F, Liu XF, Han DM, et al. Gender differences in patients with COVID-19: focus on severity and mortality. Front Public Health. 2020;8:152. https://doi.org/10.3389/fpubh. 2020.00152. 
45. Lakbar I, Luque-Paz D, Mege JL, Einav S, Leone M. COVID-19 gender susceptibility and outcomes: a systematic review. PLoS ONE. 2020;15(11):e0241827. https://doi.org/10.1371/journal. pone. 0241827.

46 Quinti I, Lougaris V, Milito C, Cinetto F, Pecoraro A, Mezzaroma I, et al. A possible role for B cells in COVID-19? Lesson from patients with agammaglobulinemia. J Allergy Clin Immunol. 2020;146(1):211-213 e4.

47. Milosevic I, Jovanovic J, Stevanovic O. Atypical course of COVID-19 in patient with Bruton agammaglobulinemia. J Infect Dev Ctries. 2020;14(11):1248-51.

48. AŞIk A, Mete GÖKmen N. COVID-19 Disease and hereditary angioedema. Asthma Allergy Immunology. 2020.

49. Belbezier A, Arnaud M, Boccon-Gibod I, Pelletier F, McAvoy C, Gobert D, et al. COVID-19 as a trigger of acute attacks in people with hereditary angioedema. Clin Exp Allergy. 2021.

50. Sharma A, Bhatt NS, St Martin A, Abid MB, Bloomquist J, Chemaly RF, et al. Clinical characteristics and outcomes of COVID19 in haematopoietic stem-cell transplantation recipients: an observational cohort study. Lancet Haematol. 2021. https://doi. org/10.1016/S2352-3026[20]30429-4.

51. Andersen KM, Mehta HB, Palamuttam N, Ford D, Garibaldi BT, Auwaerter PG, et al. Association between chronic use of immunosuppresive drugs and clinical outcomes from coronavirus disease 2019 (COVID-19) hospitalization: a retrospective cohort study in a large US health system. Clin Infect Dis. 2021. https://doi.org/10. 1093/cid/ciaa1488.

52. Foresta C, Rocca MS, Di Nisio A. Gender susceptibility to COVID-19: a review of the putative role of sex hormones and $\mathrm{X}$ chromosome. J Endocrinol Invest. 2020, https://link.springer.com/ article/10.1007\%2Fs40618-020-01383-6

Publisher's Note Springer Nature remains neutral with regard to jurisdictional claims in published maps and institutional affiliations.

\title{
Authors and Affiliations
}

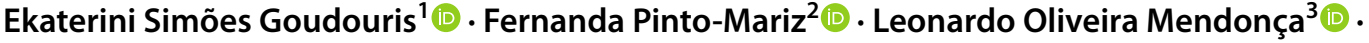

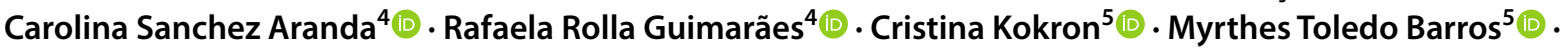 \\ Flávia Anísio ${ }^{6}$ - Maria Luiza Oliva Alonso ${ }^{7}$ () - Fernanda Marcelino ${ }^{8}$ (D) . Solange Oliveira Rodrigues Valle ${ }^{7}$ (i) \\ Sergio Dortas Junior ${ }^{7}$ (1) . Irma Douglas Paes Barreto ${ }^{9}$ (1) . Janáira Fernandes Severo Ferreira ${ }^{10}$ (1) \\ Pérsio Roxo-Junior ${ }^{11}$ (i) . Almerinda Maria do Rego Silva ${ }^{12}$. Fernanda Lugão Campinhos ${ }^{13}$ (i) . \\ Carmem Bonfim ${ }^{14}$. $\cdot$ Gisele Loth ${ }^{15}$ (D) Juliana Folloni Fernandes ${ }^{16}$. Julia Lopes Garcia ${ }^{16}$. Albertina Capelo ${ }^{17}$. \\ Olga Akiko Takano ${ }^{18}$ - Maria Isabel Valdomir Nadaf ${ }^{18}$ (D) Eliana C. Toledo ${ }^{19}$ - Luciana Araújo Oliveira Cunha ${ }^{20}$.

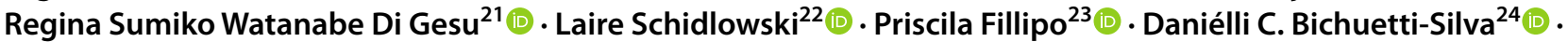 \\ Gustavo Soldateli ${ }^{25}$ (1) Natasha Rebouças Ferraroni ${ }^{26}$ (1) - Ellen de Oliveira Dantas ${ }^{27}$. Simone Pestana ${ }^{28}$.

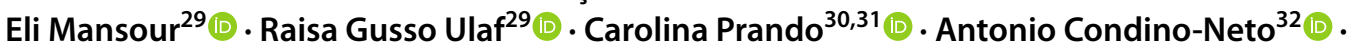 \\ Anete Sevciovic Grumach ${ }^{33}$
}

\author{
Fernanda Pinto-Mariz \\ fernandapmariz@yahoo.com.br \\ Leonardo Oliveira Mendonça \\ leonardo.oliveira.mendonca@gmail.com \\ Carolina Sanchez Aranda \\ carolaaranda@yahoo.com.br \\ Rafaela Rolla Guimarães \\ rafaela.rlg@gmail.com \\ Cristina Kokron \\ cmkokron@gmail.com \\ Myrthes Toledo Barros \\ myrtb@uol.com.br \\ Flávia Anísio \\ flaviaanisio@yahoo.com.br \\ Maria Luiza Oliva Alonso \\ mloalonso@yahoo.com.br \\ Fernanda Marcelino \\ fcmalergia@hotmail.com \\ Solange Oliveira Rodrigues Valle \\ solangervalle@gmail.com \\ Sergio Dortas Junior \\ sdortasjr@gmail.com
}

Irma Douglas Paes Barreto irmacdouglas@gmail.com

Janáira Fernandes Severo Ferreira

janairafs@gmail.com

Pérsio Roxo-Junior persiorj@fmrp.usp.br

Almerinda Maria do Rego Silva

almerindamrs@gmail.com

Fernanda Lugão Campinhos

flugao@globo.com

Carmem Bonfim

carmembonfim@gmail.com

Gisele Loth

giseleloth@hotmail.com

Juliana Folloni Fernandes

julianafolloni@gmail.com

Julia Lopes Garcia

julialopesgarcia@gmail.com

Albertina Capelo

albertinacapelo@hotmail.com

Olga Akiko Takano

oatakano@gmail.com 
Maria Isabel Valdomir Nadaf gugubibi@gmail.com

Eliana C. Toledo

elianact10@gmail.com

Luciana Araújo Oliveira Cunha

lucianaaoc@gmail.com

Regina Sumiko Watanabe Di Gesu

rwdigesu@gmail.com

Laire Schidlowski

laire.lab@gmail.com

Priscila Fillipo

pri.80@globo.com

Daniélli C. Bichuetti-Silva

imunobichuetti@gmail.com

Gustavo Soldateli

soldateli@gmail.com

Natasha Rebouças Ferraroni

nferraroni@gmail.com

Ellen de Oliveira Dantas

draellendantas@gmail.com

Simone Pestana

simpestana@yahoo.com.br

Eli Mansour

eliemansour27@hotmail.com

Raisa Gusso Ulaf

haysa_@hotmail.com

Carolina Prando

carolina.prando@hpp.org.br

Antonio Condino-Neto

antoniocondino@gmail.com

Anete Sevciovic Grumach

asgrumach@gmail.com

1 IPPMG-Universidade Federal Do Rio de Janeiro (UFRJ), Rua Professor Luis Cantanhede, 77 ap 101, Rio de Janeiro, RJ 22245-040, Brazil

2 IPPMG-Universidade Federal Do Rio de Janeiro (UFRJ), Rio de Janeiro, RJ, Brazil

3 Clinica Croce and Center for Rare Diseases At "Hospital 9 de Julho", Sao Paulo, SP, Brazil

4 Universidade Federal de São Paulo (UNIFESP), Sao Paulo, SP, Brazil

5 Division of Clinical Immunology and Allergy-Hospital das Clínicas, Faculdade de Medicina da Universidade de São Paulo (FMUSP), Sao Paulo, SP, Brazil

6 Instituto Fernandes Figueira (IFF-Fiocruz), Rio de Janeiro, RJ, Brazil

7 Serviço de Imunologia, Hospital Universitário Clementino Fraga Filho (HUCFF-UFRJ), Rio de Janeiro, RJ, Brazil

8 Departamento de Alergia E Imunologia-Hospital Regional da Asa Norte (HRAN), Brasília, DF, Brazil

9 Universidade Estadual Do Pará, Belem, PA, Brazil
10 Hospital Infantil Albert Sabin/Universidade Estadual Do Ceará, Fortaleza, CE, Brazil

11 Serviço de Alergia E Imunologia Pediátrica Faculdade de Medicina de Ribeirão Preto, Universidade de São Paulo (USP RP), Ribeirao Preto, SP, Brazil

12 Universidade Federal de Pernambuco, Recife, PE, Brazil

13 Asthma, Allergy and Immunology Reference Center, Escola Superior de Ciências da Santa Casa de Misericórdia de Vitória, Vitoria, ES, Brazil

14 Pediatric Bone Marrow Transplantation Unit, Hospital Pequeno Príncipe, Curitiba, PR, Brazil

15 Pediatric Bone Marrow Transplantation Unit, Hospital de Clinicas, Universidade Federal do Parana, Curitiba, PR, Brazil

16 Instituto Do Tratamento Do Cancer Infantil Instituto da Criança, Hospital das Clínicas da Faculdade de Medicina da Universidade de São Paulo (USP) and Hospital Israelita Albert Einstein, São Paulo, SP, Brazil

17 Universidade Federal Do Estado Do Rio de Janeiro (UNIRIO), Rio de Janeiro, RJ, Brazil

18 Hospital Universitário Júlio Müller, Universidade Federal Do Mato Grosso (UFMT), Cuiaba, MT, Brazil

19 Division of Allergy and Clinical Immunology, FAMERP, Faculdade de Medicina de São José Do Rio Preto, São José Do Rio Preto, SP, Brazil

20 Universidade Federal de Minas Gerais (UFMG), Belo Horizonte, MG, Brazil

21 Division of Allergy and Clinical Immunology, Department of Pediatrics, Hospital Criança Conceição, Porto Alegre, RS, Brazil

22 Faculdades Pequeno Príncipe, Instituto de Pesquisa Pelé Pequeno Príncipe, Curitiba, PR, Brasil

23 Hospital Municipal Jesus, Rio de Janeiro, RJ, Brazil

24 Universidade Federal de Goias (UFG), Goiânia, GO, Brazil

25 Hospital Infantil Joana de Gusmão, Florianópolis, SC, Brazil

26 Clínica Ferraroni, Brasília, DF, Brazil

27 Hospital Israelita Albert Einstein, Sao Paulo, SP, Brazil

28 Universidade Federal Fluminense (UFF), Rio de Janeiro, RJ, Brazil

29 Alergia E Imunologia, Departamento de Clínica Médica, Universidade de Campinas (UNICAMP), Campinas, SP, Brazil

30 Hospital Pequeno Príncipe, Curitiba, Brazil

31 Faculdades Pequeno Príncipe, Instituto de Pesquisa Pelé Pequeno Príncipe, Curitiba, PR, Brazil

32 Department of Immunology, Institute of Biomedical Sciences, Universidade de Sao Paulo (USP), Sao Paulo, SP, Brazil

33 Faculdade de Medicina, Centro Universitario Saude ABC, Santo Andre, SP, Brazil 